4th International Scientific Conference SEC-IASR 2019, Galati, Romania, 7th - 8th June, 2019

\title{
The Influence of Sensory Stimuli on Improving Attention and Memory in Children
}

\author{
Nela Tatiana BALINT \\ https://doi.org/10.18662/lumproc/sec-iasr2019/05
}

How to cite: Balint, N. T. (2020). The Influence of Sensory Stimuli on Improving Attention and Memory in Children. In S. Marin \& P. Moisescu (vol. eds.), Lumen Proceedings: Vol. 12. 4th International Scientific Conference SECIASR 2019 (pp. 40-49). Iasi, Romania: LUMEN Publishing House.

https://doi.org/10.18662/lumproc/sec-iasr2019/05 


\title{
The Influence of Sensory Stimuli on Improving Attention and Memory in Children
}

\author{
Nela Tatiana BALINT ${ }^{1}$
}

\begin{abstract}
The stimulus is any variation of a factor in the environment that produces stimulation, or any factor that produces or evokes an action in a nerve, muscle, gland, or other excitable tissue, or determines the activation of a function or of a metabolic process (Moțet, D., 2010: 286). The child's psychological development is not done by itself, instinctively, but through two fundamental instruments: play and imitation. Play develops the psychological processes of direct and unmediated reflection of reality - the perception (by handling various objects, the child develops the perception of size, shape, color, weight, distance, etc.) and the representations, but also the intellectual mental processes, attention, memory, thought, imagination. The aim of this study was to observe, analyze and interpret the results recorded during the application of sensory stimuli to improve attention and memory in school children of 7-10 years old. The research was based on the following working bypothesis: presumably, by using sensory stimuli one can contribute to the improvement of attention and memory in children.
\end{abstract}

Keywords: attention; memory; sensory stimuli.

1 "VasileAlecsandri" University of Bacău, Bacău, Romania, balint.tatiana@gmail.com 


\section{Introduction}

In the current context of education, memorizing the theoretical knowledge represents a fundamental part in evaluating the content of some didactic disciplines that do not correspond with the tendencies of the social environment in which children have to adapt their knowledge through practical activities. Both the attention and the memory, the first through the lack of focus and the loss of focus on information, and the second through the need to retain a large volume of information, make them an enemy in children's education.

The mental manifestations that are specific to the learning processes studied in this research are the attention and the memory. Generally, everybody knows what attention is, or rather what one refers to in everyday language when one focuses one's attention, or is told to pay attention to an object, an action or an idea [2].

Attention is not homogeneous and unidimensional, but is complex and heterogeneous, manifesting as three main forms: involuntary attention, voluntary attention, and post-voluntaryattention.

Memory is the mental process of recording, keeping, and replaying our previous experiences. Everything people experience in the present is not lost, it does not just vanishes without leaving any trace in the brain, but is crystallized so that it is later brought out to light and reused, thus contributing to the amplification of the psychological content, to the normal and effective development of human activity. A person, besides many other abilities (to think, talk, imagine, feel, want, desire), possesses also the one to retain, conserve, and reuse her own experiences.

\section{Problem Statement}

The experts' views on memory are very diverse. Thus, while some consider it a simple, banal, uninteresting mental faculty, others believe it is very significant for one's psychology, considering it fundamental, a "founding stone of one's mental life." Also, while some think the psyche is interesting only in its pathological deviations, others believe it to be a "hyper-complex system" [6].

The beginning of school represents a special period in childhood, a transition period during which there can be tensions, conflicts, major changes in the child's personality that can generate problems in the child's adaptation to the rigors of education. 
During this time, because of the new school environment, a certain timetable appears in the children's lives, certain plans, structured programs that direct their activities.

All of these specific children's activities are regulated through stimulation. The stimulus is any variation of a factor in the environment that produces a stimulation, or any factor that produces or evokes an action in a nerve, muscle, gland, or other excitable tissue, or determines the activation of a function or of a metabolic process [4: 286].

\section{Research Questions/Aims of the research}

The aim of this research was to observe, analyze and interpret the results recorded during the application of sensory stimuli to improve attention and memory in school children of 7-10 years old. This study was conducted over the course of 6 months.

This research started from the following hypothesis:

- presumably, through sensory stimuli, one can contribute to the improvement of attention and memory in children.

The research was conducted at the "Duiliu Zamfirescu" school of Focsani, during the physical education classes, when the investigations, tests, and the programs were applied. It must be said that the tests were conducted with the agreement of the psychological counselor, the teachers, the parents and the children.

The group of subjects comprised 60 ten-year-old children, 30 in the experimental group and 30 in the control group, 30 girls and 30 boys.

Measurement is the process of attributing values to certain properties of the subject, according to certain rules so that the numerical relationships to represent relevant relationship between them.

Throughout the research, two tests were conducted to gather relevant data regarding the development level of the subjects' attention and memory.

The attention and motor memory assessment test - it assesses the attention disorders when there is a large number of mistakes in reversing the the graphical signs corresponding to the test images, or memory disorders when certain signs are omitted [5].

The REY attention and auditory memory assessment test conceived by Andre Rey, it assesses the attention and auditory memory. It contained 6 phases - 5 to reproduce and one to recognize.

The physical therapy sessions had a duration of 40 minutes, being conducted 2 times per week. The games were performed slowly, at the subjects' own pace, with short breaks of 10-15 seconds. 
The used means were chosen according to the classification of sensations:

- External sensations - the ones providing information regarding the external stimuli;

- Internal sensations - the ones providing information regarding modifications in the internal state of the body;

- Proprioceptive sensations - the ones providing information regarding the body position and movement [3];

External elements - light touch, temperature;

Proprioceptive elements - vibration, telescoping, traction, acceleration, and rhythmic rolling;

Combined proprioceptive and external elements - manual contacts and pressures on long tendons;

Tele-receptive elements - sight, hear, smell;

Internal elements - head position lower than the body position (stimulating the carotid sinus)

In the structure of mental activities, the game is a form of activity originating in early ontogenesis. The child's psychological development is not done by itself, instinctively, but through two fundamental instruments: play and imitation. The research used drill games, symbolic games, games with rules.

\section{Research Methods}

Measurement is the process of attributing values to certain properties of the subject, according to certain rules so that the numerical relationships to represent relevant relationship between them.

Throughout the research, two tests were conducted to gather relevant data regarding the development level of the subjects' attention and memory.

The attention and motor memory assessment test - it assesses the attention disorders when there is a large number of mistakes in reversing the graphical signs corresponding to the test images, or memory disorders when certain signs are omitted [1].

The REY attention and auditory memory assessment test conceived by Andre Rey, it assesses the attention and auditory memory. It contained 6 phases - 5 to reproduce and one to recognize.

The physical therapy sessions had a duration of 40 minutes, being conducted 2 times per week. The games were performed slowly, at the subjects' own pace, with short breaks of 10-15 seconds.

The used means were chosen according to the classification of 
sensations:

- External sensations - the ones providing information regarding the external stimuli;

- Internal sensations - the ones providing information regarding modifications in the internal state of the body;

- Proprioceptive sensations - the ones providing information regarding the body position and movement [3].

External elements - light touch, temperature;

Proprioceptive elements - vibration, telescoping, traction, acceleration, and rhythmic rolling;

Combined proprioceptive and external elements - manual contacts and pressures on long tendons;

Tele-receptive elements - sight, hear, smell;

Internal elements - head position lower than the body position (stimulating the carotid sinus)

In the structure of mental activities, the game is a form of activity originating in early ontogenesis. The child's psychological development is not done by itself, instinctively, but through two fundamental instruments: play and imitation. The research used drill games, symbolic games, games with rules.

\section{Findings}

As a result of the kinetotherapeutic intervention we are able to present the obtained results. Through the graphical presentation we highlight the results of the experimental batch.Figure 1 shows the progression that is recorded after the test is in the percentages being $49.12-68.3 \%$ and in the end the percentage being $63.7-72 \%$ of the sub-items in the experimental group, in the test of attention evaluation and memories motrice.

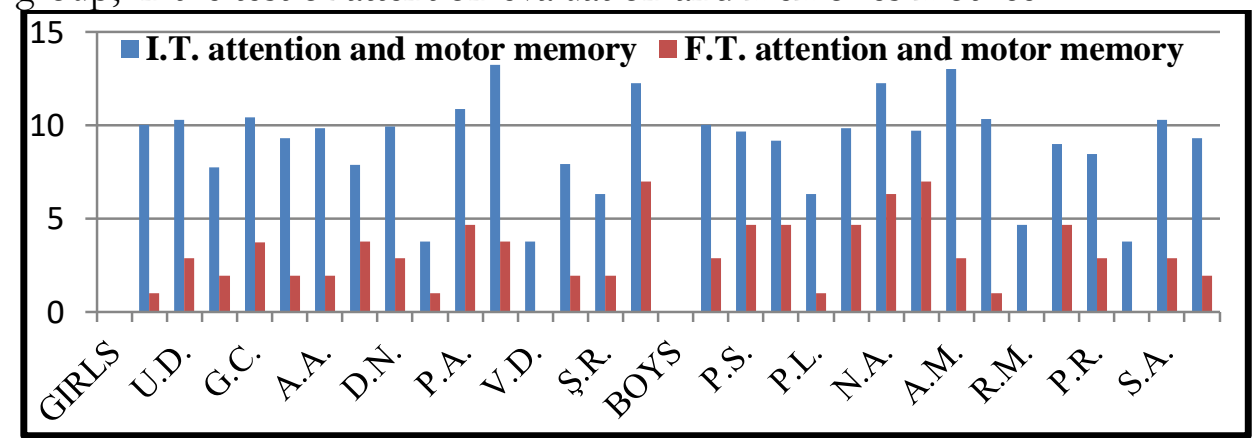

Figure 1 The initial and final testing of the leftover deficit during the attention and motor memory assessment test 
Figure 2 evidence also shows that, following a test, this percentage is between 49.12 - 64.7\% and with a smaller progression between 49.12 $66.5 \%$ of the subjects in the control group in the attention assessment test and their memory motions.

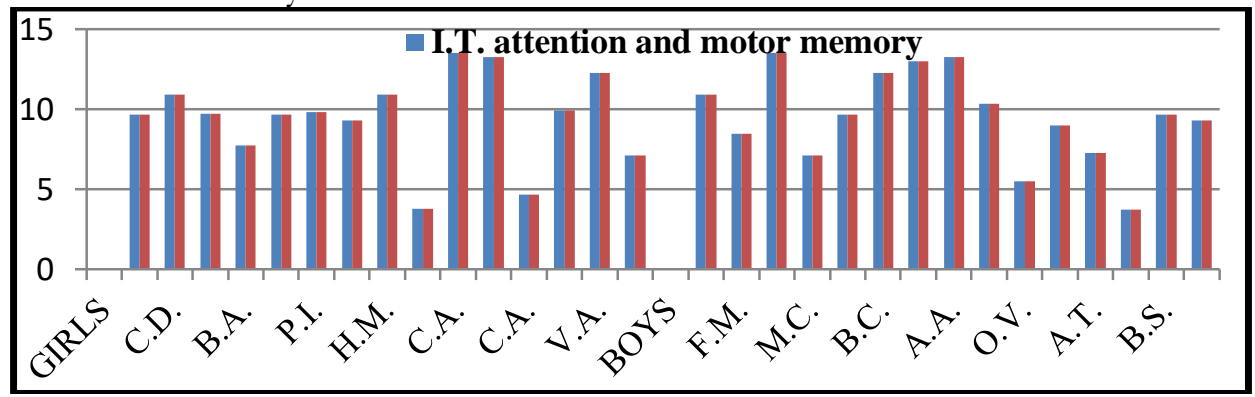

Figure 2 The initial and final testing of the leftover deficit during the attention and motor memory assessment test

The test for assessing attention and motor memory, based on voluntary attention, visual memory, mechanical and logical, we note a score of more than 49 points and a maximum of 68 points for testing in the initial, after the test, at the end of the test. an increase of these psihice qualities with a minim score of 63 points and a maxim of 72 points for the subject in the experimental group, compared to that of the subjects in the control group.

In the remaining deficit of the same test calculated as a percentage, we notice after testing it a minimum of $3.78 \%$ and a maximum of $13.25 \%$, and in the final test we notice a minimum of $6.32 \%$ and a maximum of $0 \%$, with a lot of experts, compared with the expert. that of the sub-items in the control group.

Figure 3 highlights the progress of the experimental group subjects in the Rey attention and auditory memory assessment test, phase 1.

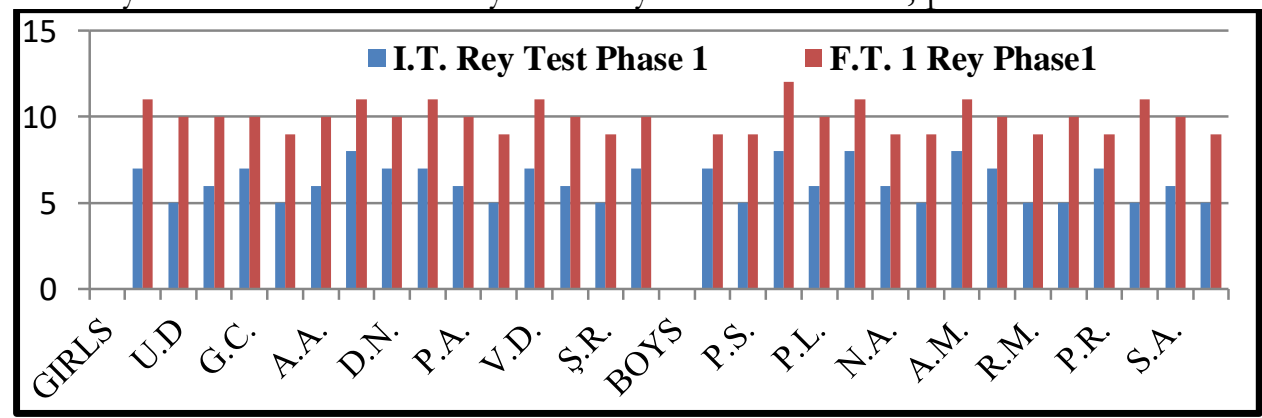

Figure 3 Initial and final testing - the Rey test, phase 1 
Figure 4 highlights the progress of the experimental group subjects in the Rey attention and auditory memory assessment test, phase 2 .

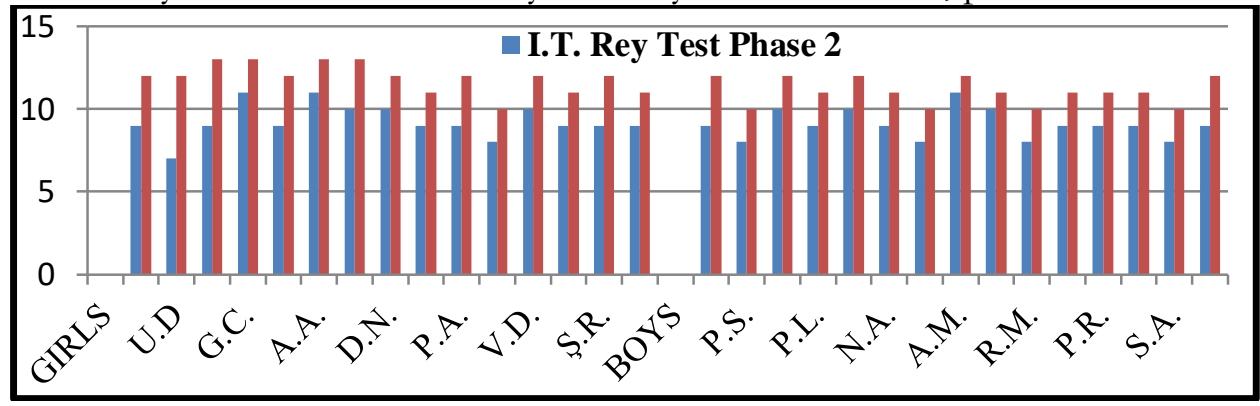

Figure 4 Initial and final testing - the Rey test, phase 2

Figure 5 highlights the progress of the experimental group subjects in the Rey attention and auditory memory assessment test, phase 3.

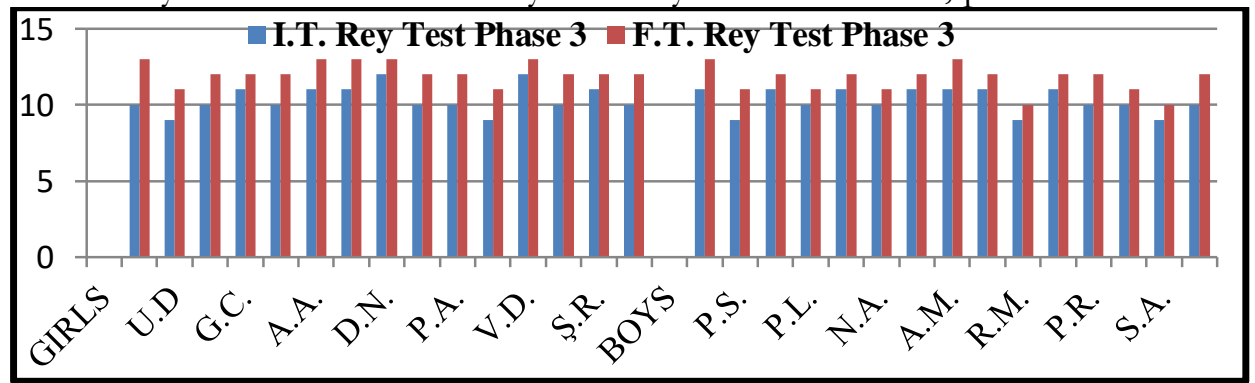

Figure 5 Initial and final testing - the Rey test, phase 3

Figure 6 highlights the progress of the experimental group subjects in the Rey attention and auditory memory assessment test, phase 4.

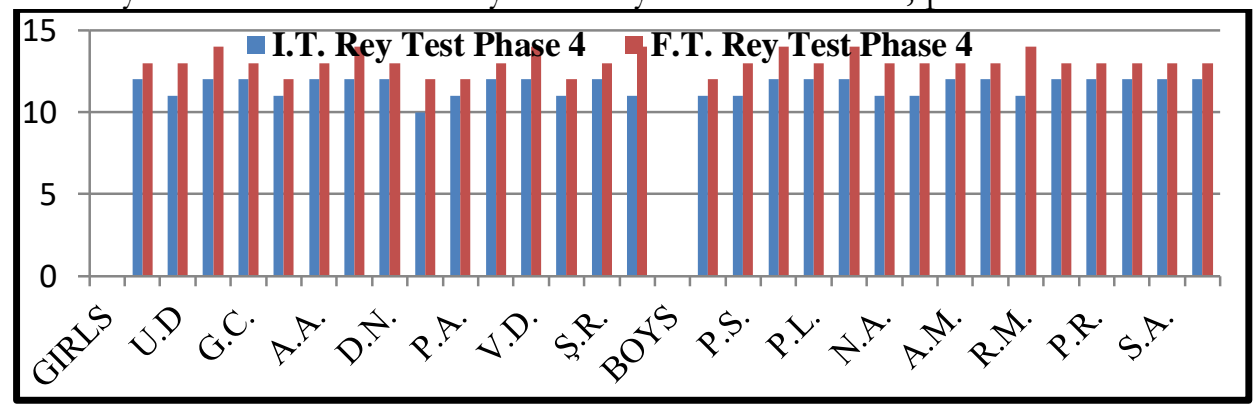

Figure 6 Initial and final testing - the Rey test, phase 4

Figure 7 highlights the progress of the experimental group subjects in the Rey attention and auditory memory assessment test, phase 5. 


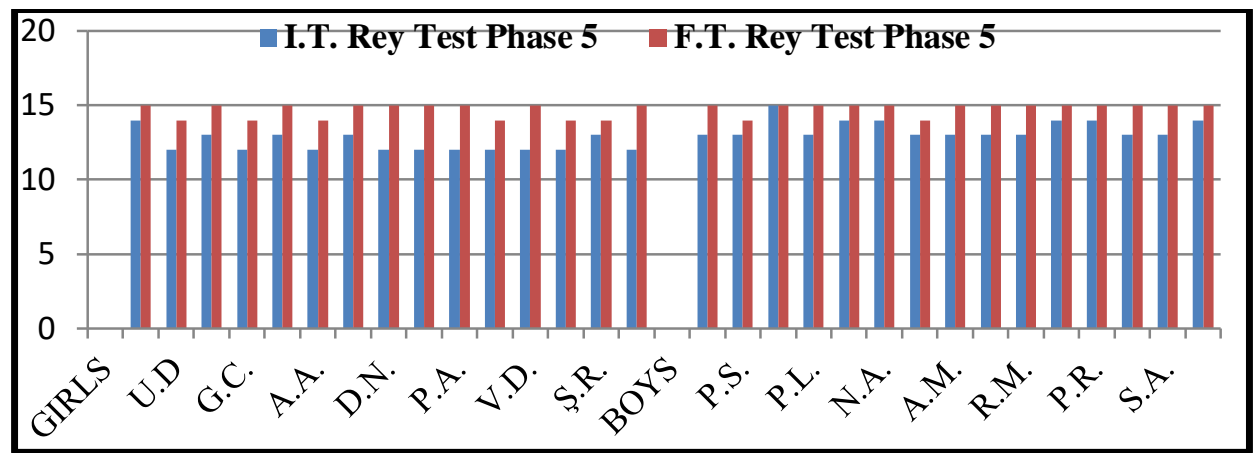

Figure 7 Initial and final testing - the Rey test, phase 5

Figure 8 highlights the progress of the experimental group subjects in the Rey attention and auditory memory assessment test, phase 6 .

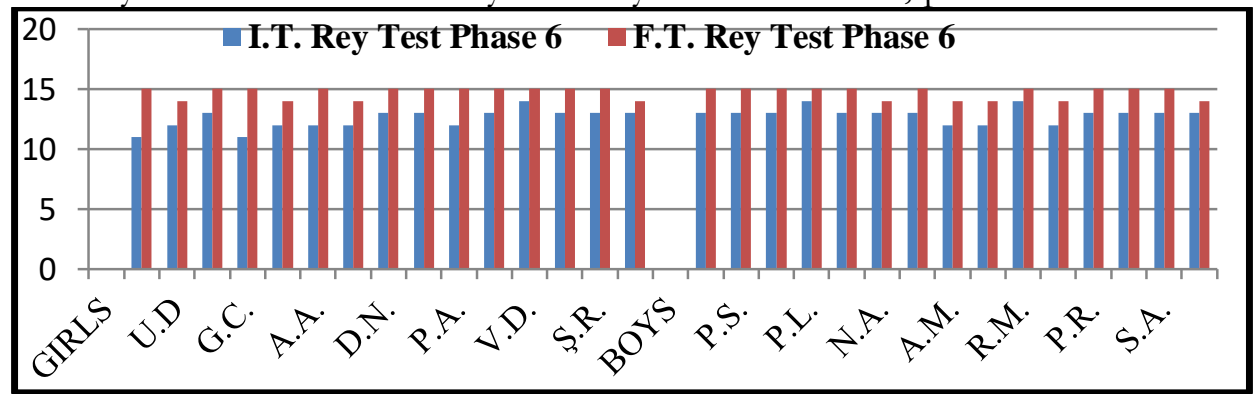

Figure 8 Initial and final testing - the Rey test, phase 6

Figure 9 highlights the regression of the control group subjects in the Rey attention and auditory memory assessment test, phases 5-6.

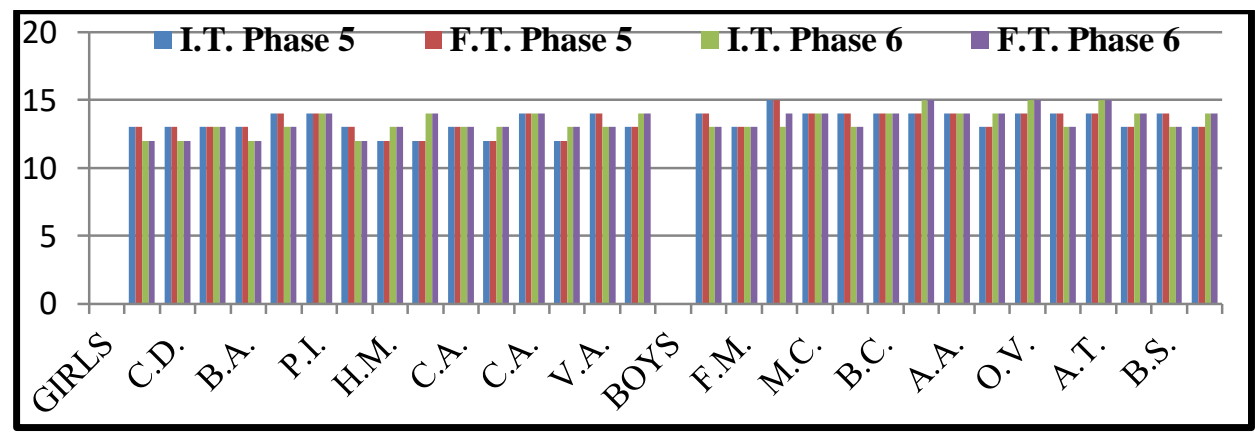

Figure 9 Initial and final testing - the Rey test, phases 5-6 (control group)

The test of evaluation of the attention and memory is audited by Rey, being composed of five phases of recognition and one of reproduction, during the 5 phases of recognition when testing in the end and in the end, 
the evolution of the test in the study is noted in the sub-course. In this subsection, they encountered mici dificultăţi, following the application of the specifice game players at the final test we note the progress of the subsections according to graph no. 3-8 and table 7, compared to the control lot subject according to graph no. 9 and table no. 8 .

When analyzing the results presented above, we note the essential role of the practice of games, which have an extraordinary effect in the development of the psychological qualities at 10 years old, according to the graphs displayed and the presence of the subordinated teams in the event.

\section{Discussions}

After the implementation of the methodology, there was an improvement in the experimental group subjects' attention and memory, as one can see in the initial and final test results.

Following the initial and final tests, the control group, which did not benefit from any prophylactic physiotherapy program, did not record any modification in their mental abilities.

In regard to the attention and motor memory assessment test, the experimental group subjects recorded a minimum score of 49 points and a maximum one of 69 points during the initial testing, while after the application of the game programs, during the final testing there was an increase in the subjects' abilities, recording a a minimum score of 63 points and a maximum one of 72 points, as presented in table 5 , in comparison with the control group, presented in table 6 .

In regard to the leftover deficit for the same test, in percentages, there was during the initial testing a minimum of $3.78 \%$ and a maximum of $13.25 \%$, and during the final testing a minimum of $6.32 \%$ and a maximum of $0 \%$, recorded by the experimental group, as presented in figure 1 , in comparison with the control group, presented in figure 2 .

In regard to the Rey attention and auditory memory assessment test, one can see the progress of the experimental group subjects: in the reproduction phase, during the initial testing, the subjects encountered small difficulties, while after the application of the game programs, during the final testing, the progress of the subjects can be seen in figures 3-8 and table 7, in comparison with the control group subjects, presented in figure 9 and table 8.

One can observe the essential role played by the games, which had an extraordinary effect in developing the mental abilities in 10-year-old children, as shown in the tables and figures above; obviously, the control group subjects 
Nela Tatiana BALINT | Lumen Proceedings 12 | SEC-IASR 2019

have played a significant role in highlighting the importance of the games.

\section{Conclusions}

At the end of the research, it can be said that the initial hypothesis was confirmed: by selecting and applying specific games, through sensory stimuli, one can contribute to the improvement of attention and memory in children.

On the basis of the recorded results, the following conclusions can be drawn:

- the intervention took into account the subjects' age and the complexity of the selected games; over the course of the research there was a significant progress in the experiment group children - in the end, they recorded a better precision in their performance, team work, coordination, attention and spatial orientation;

- games and physical activity in general result, in addition to the increase of the articular mobility, the formation of reflexes of correct bodily attitudes, the development of the muscles, the harmonious development of the body, the adaptation of the body to the effort, the training and the movement of the body. for the child to increase these qualities in the game, the extraction and interaction with other children is highlighted during the games and the program established by the experiment group.

The final conclusion to be drawn is that in addition to satiety and the pleasure of playing, games have a consensual effect on their psychotropic aptitude, on their personalities and character traits. Also, the games are an important link in the chain of actions that influence the enhancement of psychic abilities, combining harmoniously the educational and educational element with the interactive and playful element.

\section{References}

[1] Balint T. Evaluarea dezvoltării senzorio-motrice. Master's course. Bacău: Editura Alma Mater; 2016. pp. 201-202.

[2] Floru R. Atenția. Bucharest: Editura Orizonturi; 1976.7 p.

[3] Mareş G. Psihologia activităților motrice. Lecture notes. Bacău; 2012. pp. 25-26.

[4] Moțet D. Bazele teoretico-metodice ale exercițiului fizic în kinetoterapie. Lecture notes. Bacău: Editura Universităţii; 1995.

[5] Moțet D. Enciclopedia de kinetoterapie. Vol. I-II. Bucharest: Editura Semne; 2009. 286 p.

[6] Zlate M. Fundamentele psihologiei. Iaşi: Editura Polirom; 2009. pp. 6-7. 